\title{
A Brief Analysis on the Steel Structure Construction of High-rise Building
}

\author{
Zhiwei Cai \\ Naval Architecture and Ocean Engineering School, Wuhan Institute of Shipbuilding Technology, \\ Wuhan Hubei, 430050, China
}

Keywords: High-rise building, Steel structure construction technology, Application.

Abstract. Steel structure is widely used in modern high-rise building construction for its strong advantages. In order to improve the technical level of high-rise building steel structure construction, this paper mainly discusses its construction technical points.

\section{Analysis on the technical features of high-rise steel structure construction}

In modern high-rise construction, steel structural system is widely used, this is mainly because of that it not only has large strength, but also has good appearance, and can ensure the construction progress. For example, large-scale high-rise buildings like Beijing China Central Television (As shown in figure 1) and Wuhan Minsheng Bank Building(As shown in figure 2) all adopt steel structure. Main features of these high-rise steel structure construction can be summarized into the following aspects: 1 . Project quantity of steel structure is large, and with many components, the place for stacking components and the construction site is small; 2. It usually requires for vertical crossing construction; 3. The steel structure installation standard for high-rise building is high, with high requirements on steel selection, measurement and welding procedures; 4. Many factors influence construction, such as nature, material, technology and so on; 5. large machinery is needed for installation, especially tower crane, hire requirements are needed in installation, elevating and tearing down.

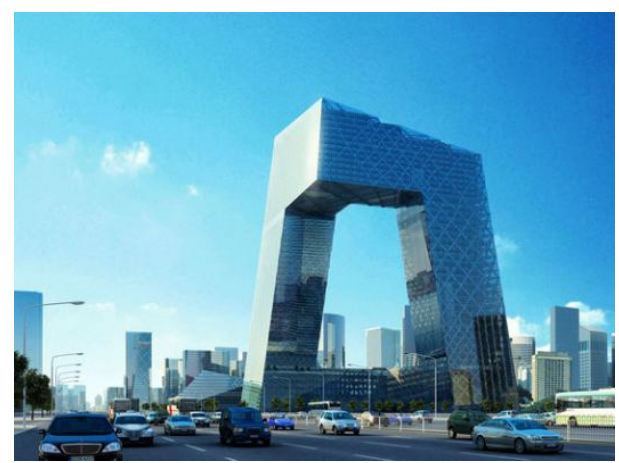

Fig. 1. Beijing China Central Television

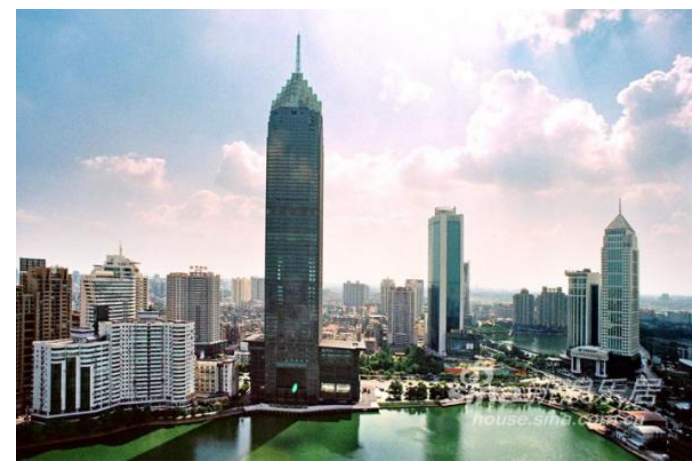

Fig. 2. Wuhan Minsheng Bank Building

\section{Technical points in the construction preparation stage of high-rise building steel structure}

\section{Key points of construction organizing preparation.}

First to elaborately write the construction organization design, ensure the effective combination of design concept and construction; second to effectively perfect the construction and acceptance standard, ensure that behaviors and responsibilities are effectively clear; third to strengthen the carrying out of construction technique test and procedure qualification work, provide technical guarantee for the whole construction task.

\section{Technical points of hoisting preparation.}

Hoisting preparation mainly means to prepare the crane needed in the construction, commonly are tower crane and jack-up crane (As shown in Figure 3-5). Thereinto, the former mainly has luffing jib tower crane and balance tower crane, the latter mainly has outside attached crane and 
inside-self-elevating type tower crane. In actual construction, in order to meet performance needs, we have to pay attention to problems from the following aspects: parameters, such as the maximum elevating capability and load moment, hoisting height, maximum radium and minimum radius, must be clear to meet actual needs. Especially that when enlarge hoisting height and hoisting distance, its real elevating capacity will be decreased, thus must prepare well to prevent project delay even safety accidents caused by poor preparation, this is necessary to be noted.

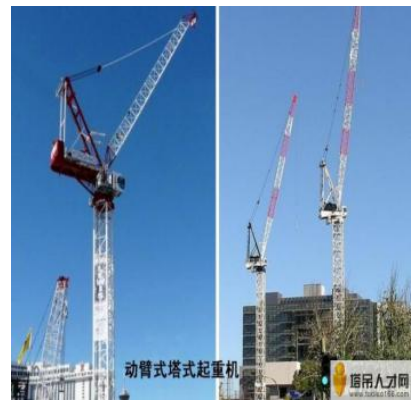

Fig. 3

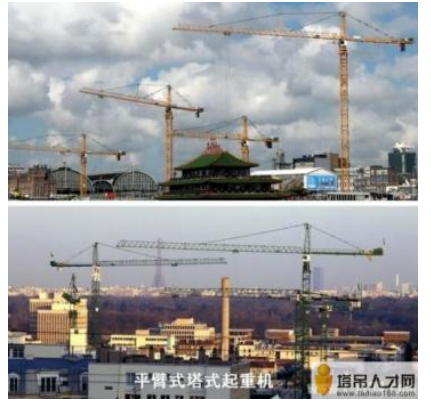

Fig. 4

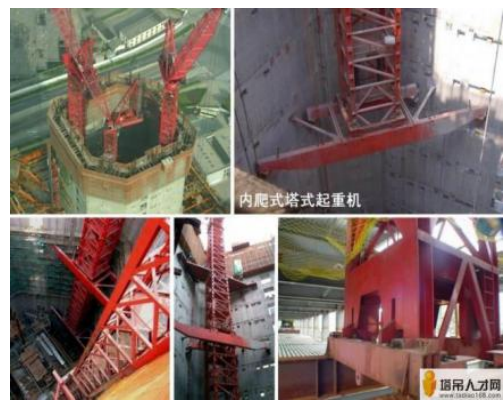

Fig. 5

\section{Technical points of construction site preparation.}

Before the implementation of high-rise steel structure construction, following preparations must be down well: 1 . Prepare instruments and equipment for inspection and measurement and for measuring steel components and parts; 2. Complete foundation retest; 3. Timely transport steel components to the construction site and reasonably arrange stacking; 4. Finish the selection and matching of construction equipment; 5 . Complete every construction organization design; 6 . Strengthen technical disclosure of the construction site, clarify the technical quality and safety responsibility $^{[1]}$.

\section{Summary of specific construction technical points}

\section{Specifically divide water period.}

In the high-rise steel structure building construction, in order to meet steel structure's requirements on hoisting and fabrication, we have to divide water period for the building from height direction, the division basis is normally the steel column section, and to meet its monomer characteristics at the same time with meet the design requirement of steel structure. During the hoisting process, not only need to guarantee the severity of single frame, but also need to ensure the stability of the elevating frame of the crane. Therefore, in order to guarantee the scientific division of water period, the followings must be paid attention to: 1 . The elevating performance of crane must meet the requirement that load the heaviest object in the water period; 2 . The hoisting height of crane must be the hoisting height needs of the components in next water period; 3 . The column length of each water period must conform to the production and transportation needs of the component manufacture.

\section{Technical points of standard knot frame installation.}

1) Technical points

When install standard knot in the high-rise steel structure buildings, mainly adopt the following installation technology: (1) Internodes comprehensive installation technology; (2) Assembly line installation technology. In actual construction, we shall combine engineering actual needs, strengthen its application, while there must be some advantages and inadequacy in the installation, therefore, we must ensure the timely supply of components and ensure the quality, normally, only if the technology is good, it can get good results. Technology (1), mainly to choose a internode among standard knots to be the standard internode, then to complete the installation of four steel columns, timely install frame beam, secondary beam and the carriage, complete to install the spacial standard internode from the bottom up, meanwhile to finish the work of correction and fixation in time, then to gradually enlarge frame, normally installing two steel tubes needs to install one internode, until finish the whole 
building construction. This technique has strict management requirements on the construction site and the component transportation must be smooth to ensure the stable and high effective transportation of steel components to achieve best results. Technology (2), first to install steel column in the frame of standard knots, then to install frame, use layer as unit, complete to install the whole frame from bottom up. This mainly considers that components supply is influenced by many factors, installation can be guaranteed even when the supply is not ensured, which can meet the site real installation and construction.

2) Construction points

In the installation process of standard knots frame, there are many construction matters need to be noted, only note the following matters can ensure the installation quality.

Firstly, during the hoisting process of each frame, first to assemble it into a whole frame, then to install minor components, try to avoid the long time cantilever state of the single column, thus can ensure the early formation of frames to ensure the strong stability of the whole hoisting.

Secondly, when install each frame, normally we should adhere to the principle of bolt first then weld, according to the order from top beam to bottom beam at last middle beam to install, ensure the effective control of frame installation quality.

Thirdly, before welding each frame beam, to analyze whether its verticality reaches standard or not, whether there is deviation, if there is big deviation, we should reasonably select the welding in order to prevent the shrinkage drain after welding thus to reduce the column verticality deviation to the lowest level.

Fourthly, mental plate and steel stair in each frame shall be timely installed with the frame hoisting thus to ensure the effective enhance of partial vertical ascent and horizontal channel, at the same time, it can give full play of its function of security isolation to provide convenience for the operation on the construction site.

\section{Technical points of special knot frame installation.}

There is big difference between this kind of frame and the standard knots, it is special on the structure, this is mainly to better meet the special building needs and its structure in reality, therefore, different construction centers must make specific construction technique plan for hoisting special components to better ensure its installation quality. For example, the grid structure of podiums is with large span, and are mainly constructed in the high-rise building and beside it, thus the construction condition is usually very bad, therefore, during the installation process, mainly use installation on the ground or the way of integrated hoisting or on the basis of platform building, install in aloft or half aloft. If install the truss first, because of its heavy structure, it is difficult to hoist it structure as a whole, thus need to use segmental hoisting, integral elevation and partial installation to install.

\section{Technical points of steel column installation.}

Before installing steel column, first to recheck the elevation and axis of the next column, timely revise and regulate the existing error, and before the installation, install the steel ladder on the steel column on the ground.

Technical points of steel beam and steel truss installation.

Firstly, before installation, check the adapting piece on the steel column, built-in fitting of the concrete core tube, main to check whether the flatness of adapting piece meets the standard, check whether the screw hole is on the right position, the friction surface condition and the position and cleanness and flatness of the built-in fitting. Secondly, before hoisting, install the grab rail on the beam surface, or handrail and manrope, must install girder and primary truss, while needle beam or secondary beam should combine the real needs to install pointedly, the height of ordinary handrail is 1 meter, and set up with the beam length to be a channel for constructors. Thirdly, during the whole installation process, mainly use the way of two hanging points, commonly are slings for lifting loads, tie-up method and set lifting lug on the beam column.

\section{Installation of special steel structures.}

During the installation process of high-rise building steel structures, there are normally many special steel structure installation, this is mainly because that this kind of steel structure is with multiple forms, and most of them are assemblies, not only with dead load but also with big volume, 
the assemble models are pretty complicated, it has high requirements, especially its specific functions on the whole steel structure construction, and different special structures have differences on installation methods, thus the installation is difficult, therefore, must combine reality to strengthen analysis on it, use pointed technical points. The author will analyze several common special steel structures and their technical points in the followings.

Firstly, when install transitional column and transition truss, because of its heavy structure it mainly in the middle of the building. Therefore, during its installation process, mainly use methods of elevating, partial hoisting and hoisting, combine with reality to be specifically ensured. For example, in the steel structure construction engineering of one high-rise building, its span is a 43 meters large-scale truss, mainly three layers, the weight of each truss is 120 tons, thus on the basis of analysis, the constructor divide it into three sections, install it by using the section methods. When install the first truss, mainly use tower crane with luffing boom to divide the truss into three sections, during the section process, first to install the two sides of the 20 tons truss, the middle section is hoisted with two tower crane with luffing boom, with a weight of 55 tons, while when install the second and the third truss, mainly use the original structure as supporting platform, and install with partial installation. The specific installation pictures are as shown in Figure 6 and 7 and 8.

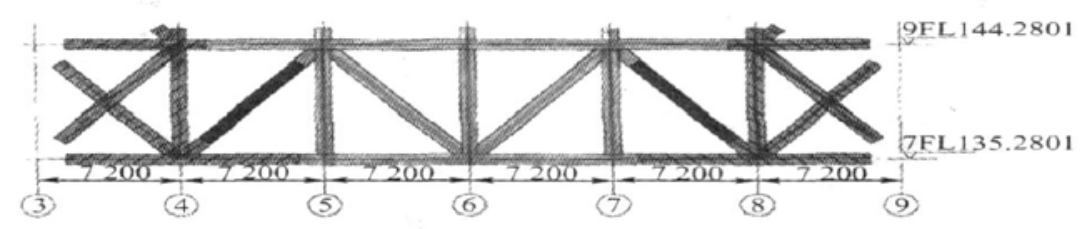

Fig. 6. Installation Instruction of the First Truss
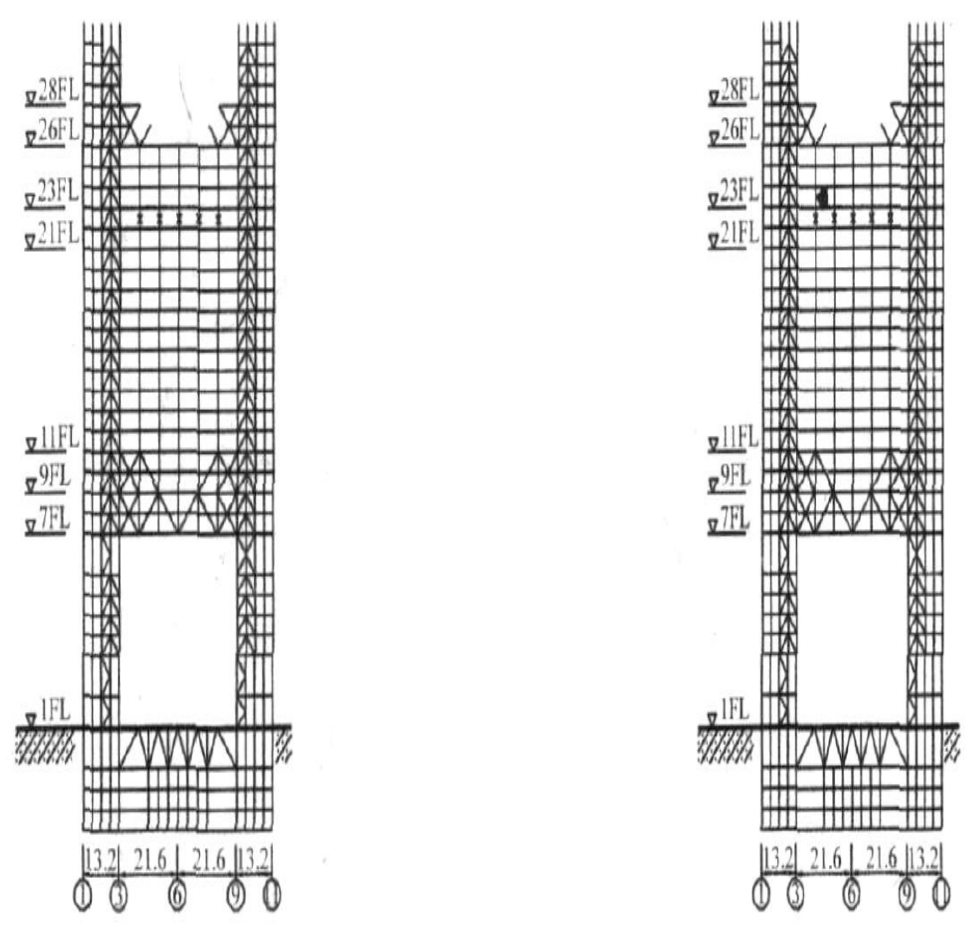

Fig. 7. Installation Instruction of the Second Truss Fig. 8. Installation Instruction of the Third Truss

Secondly, when install the spire, because the spire is the commanding height of a building, while cranes are difficult to reach this height, it is with great construction difficulties, thus need to combine real needs to strengthen treatment on it. For example, when the spire construction belongs to long distance and large tonnage, then install it with the hoisting method. While if the roof construction site is large, and the weight of truss is between 20 and 30 tons, the spire shall be constructed with sheet piling method. While spire with weight of $0 \sim 3$ tons and within 5 meters, it can be installed with partial installation method. Besides, there are lifting method and header method. For example, when use 
lifting method, mainly to plays its own advantages, use lifted town crane to complete the spire construction. While header method is mainly used to install embed fixed spire.

Thirdly, when install external truss, because of its heavy weight, using large-scale tower crane is difficult to get close to the hoisting, mainly to elevate on the basis of ground installation, commonly used equipment is steel wire type hydraulic lifting device, therefore, when use it to hoist external truss with long distance and heavy weight, it not only safe, but with strong practicalness, especially with high accuracy, which leads to its effective application in practical engineering ${ }^{[2]}$.

\section{Technical points of measurement and correction}

On the basis of steel structure installation, in order to ensure installation quality, to timely strengthen its measurement and correction, the following will analyze its technical points.

Firstly is to see from the correction process, mainly correct according to the water period, and divide water period according to the column, each water period is divided into three layers, with height of 12 meters, after completing one water period, we should timely strengthen its correction, and timely get into the installation of the next water period after correction, until finishing the installation of the whole water period, the correction should be completed accordingly.

Secondly is the correction method, mainly in following aspects: the first kind is to adjust the elevation of the ground steel structure, the first steel structure should be installed on the basis of concrete, and screw nut with each foundation bolt before installing steel column, then to install the steel column and its plate, and recheck the vertical flatness of plate and steel column, during the height transmission of each layer, timely adjust the errors with spanner to reach the actual requirement. While another method is mainly to adjust the elevation of the column top, and analyze its reasons for errors, if the elevation is high, thus should to take the length error of the latter column, if the elevation is insufficient, it should be clogged with steel plate with a certain thickness, require steel plate and steel column use the same material ${ }^{[3]}$ to ensure the same elevation of the same layer.

\section{Conclusion}

In conclusion, the construction technology of high-rise steel structure is a professional technology, it has high requirements on construction enterprises, therefore, in order to ensure engineering quality, we have to grasp the technical points in the steel structure construction, and complete all the preparatory work and strengthen technology and quality management at the same time, strengthen measurement and correction to ensure construction quality.

\section{References}

[1] Wan Rongtao. A Brief Analysis on the Construction Technology of High-rise Building Steel Structure, Zhejiang Construction, 2009,03:33-37+58.

[2] Cui Xiaoqiang, Hu Yuyin, Wu Xinzhi. Key Techniques and Measures on the Construction of Super High-rise Building Steel Structures, Construction Mechanization, 2009, 06:45-48+55.

[3] Li Pengfei. Analysis on the Technical Points of High-rise Building Steel Structure Construction, Jiangxi Building Materials, 2014, 21: 110. 